\title{
AS OBRAS DE FREI LUÍS DE GRANADA E A ESPIRITUALIDADE DE SEU TEMPO: A LEITURA DOS ESCRITOS GRANADINOS NOS SÉCULOS XVI E XVII NA PENÍNSULA IBÉRICA ${ }^{1}$
}

\author{
Célia Maia Borges (UFJF) ${ }^{2}$ \\ Universidade Federal de Juiz de Fora (Brasil)
}

\begin{abstract}
RESUMEN: Las obras del dominico Fr. Luis de Granada conocerán amplia circulación en la Península Ibérica en la segunda mitad del siglo XVI y el principio del XVII. Sus escritos fueron leídos por religiosos y laicos. Su énfasis sobre la oración mental y el valor del conocimiento afectivo en sus obras contribuirán a la difusión de sus escritos, puesto que el interés por la espiritualidad mística era grande en aquel tiempo. Sus obras conocerán una gran difusión e influirán decididamente sobre muchos de los místicos contemporáneos.
\end{abstract}

PALABRAS CLAVE: Fray luis de Granada, libros, Península Ibérica.

ABSTRACT: The works written by the Dominican Luís de Granada have achieved wide circulation in Iberian Peninsula by the second half of the sixteenth century and at the beginning of the first. His writings were read by religious and lay men. They emphasized the valorization of affective spirituality and mental prayer, which contributed to the diffusion of his writings. That occurred due to the great interest in mystical spirituality in the period. His works influenced enormously many of the spiritual men of his time.

KEYWORDS: Fray Luis de Granada, readings, Iberian Peninsula.

\section{INTRODUÇÃO}

Interessada em conhecer a influência de Frei Luís de Granada sobre os espirituais de seu tempo, mas principalmente sobre Teresa de Ávila que já venho

\footnotetext{
${ }^{1}$ Recibido el 7 de agosto, aceptado para su publicación el 22 de septiembre de 2009.

${ }^{2}$ Doutora em História. Prof ${ }^{a}$ do Programa de Pós-Graduação em História da Universidade Federal de Juiz de Fora (Brasil) e professora colaboradora do Programa de Pós-Graduação em Ciência das Religiões desta mesma Universidade. $O$ trabalho ora apresentado integra parte da pesquisa desenvolvida para o pós-doutorado realizado na Universidade Nova de Lisboa. É autora dentre outros trabalhos do livro Escravos e Libertos nas Irmandades do Rosário. Juiz de Fora: Ed. Da UFJF, 2005.
} 
pesquisando há bastante tempo, decidi-me a estudar os escritos do dominicano espanhol de modo a entender quais as correntes de pensamento da espiritualidade européia presentes no autor granadino e a sua influência nos contemporâneos no século XVI e séculosr subsequentes.

As repetidas e abundantes edições dos seus livros já por si se revelavam um indício da grande penetração das suas idéias, pelo menos entre as camadas cultas; e foi, portanto, com o objetivo de conhecer a força do seu pensamento que resolvi debruçar-me sobre os vários textos onde o autor granadino era citado. Dentro desta linha, adotei como método: a) proceder à leitura de livros de escritores espirituais de seu tempo e compará-los com os textos granadinos; b) buscar as orientações adotadas nas fundações das casas conventuais e as leituras recomendadas; c) investigar nas várias crónicas das ordens religiosas a influência dos textos de Frei Luís de Granada. Interessava-me conhecer a circulação e o grau de leituras que se fazia dos seus escritos na Península Ibérica, se bem que este trabalho contemple mais a realidade portuguesa. As fontes consultadas integram acima de tudo os fundos do acervo da Biblioteca Nacional de Portugal e do Arquivo Nacional da Torre do Tombo em Lisboa.

\section{A CIRCULAÇÃO A APROPRIAÇÃO DAS OBRAS DE FREI LUÍS DE GRANADA}

No século XVI, o dominicano espanhol Frei Luís de Granada exerceu grande ascendência sobre os seus contemporâneos na Península Ibérica, não só entre religiosos mas também entre leigos. Os seus livros conheceram várias edições em meados do século XVI e, inclusive, na segunda década do século seguinte ${ }^{3}$. De tal modo que diferentes religiosos, de distintas ordens, mencionaram os seus escritos. O seu nome circulava pela Europa Católica bem como pelas colônias iberoamericanas. Já na primeira metade de Setecentos, o licenciado espanhol Luis Muñoz se aplicou em elaborar um inventário minucioso de todos os que entraram em contato com a obra do mestre granadino ${ }^{4}$, tendo destacado que os livros do dominicano conheceram várias edições em francês, italiano, alemão e latim ainda

\footnotetext{
${ }^{3}$ Ver os catálogos das obras impressas em Portugal nos séculos XVI e XVII: Antonio Joaquim Anselmo. (1926). Bibliografia das Obras Impressas em Portugal no Século XVI. Lisboa: Oficinas Gráficas da Biblioteca Nacional. [existem edições mais recentes]. Do séc. XVII: João Frederico de Gusmão AroucA. (2003). Bibliografia das Obras Impressas em Portugal no Séc. XVII. Lisboa: Biblioteca Nacional.

${ }^{4}$ Luis MuÑOZ. (1639). Vida y Virtudes Del Venerable Varon El P.M. Fray Luis de Granada, de la Orden de Santo Domingo. En Madrid. Por Maria de Quiñones.
} 
em vida do próprio autor ${ }^{5}$. O Guia de Pecadores, por exemplo, publicado em Portugal, foi traduzido para o italiano e logo para o latim, seguindo-se uma edição em Veneza em 1576 e duas outras em Colônia em 1587 e $1590^{6}$.

De fato, o êxito editorial foi enorme tanto na Península Ibérica como na França $^{7}$, onde São Francisco de Sales recomendava a leitura das obras granadinas ${ }^{8}$. Também na Itália se traduziram e publicaram diversas obras. Os livros mais apreciados eram os que guiavam no caminho da contemplação e, nesse sentido, o Libro de la Oración y Meditación obteve inúmeras edições e em cada uma delas constam os vários modelos de exercícios de oração mental. Em 1595, sete anos após a morte de Granada, veio à luz em Veneza o livro Memorial, em língua italiana, com um prólogo do Joannini Capuano que faz a apresentação do autor? . No ano de 1605 apareceu um pequeno livro, de Frei Francisco Diogo, dando notícia da vida do frei dominicano e dos seus livros ${ }^{10}$. O nome de Granada foi mencionado em várias crônicas de ordens religiosas, quer de Dominicanos, quer de Jesuítas, quer de Carmelitas Descalços e Agostinianos.

A fundadora do Carmelo Descalço, Teresa de Ávila, orientava as suas monjas para a leitura dos livros de Granada e incitava as bibliotecas do mosteiro a ter as suas obras. Ela mesma em carta ao dominicano espanhol declarava a sua admiração por ele «hacer escrito tan santa e prevechosa doctrina e por haberlo dado Dios al mundo para tan grande y universal bien de las almas» ${ }^{11}$.

Vários livros do mestre granadino compunham o acervo da biblioteca do Mosteiro de Santa Cruz do Bussaco [grafia antiga], único eremitério dos

5 Segundo o autor seiscentista Luiz Munõz, algumas das obras de Luís de Granada foram traduzidas para o japonês. Todavia, não foi possível averiguar o alcance das traduções mencionadas por este autor.

${ }^{6}$ Luis MuÑOZ. Vida y Virtudes... op.cit. p. $175 \mathrm{v}$.

${ }^{7}$ Algumas obras de Frei Luis de Granada podiam ser encontradas em bibliotecas conventuais de França no séc. XVII. Dentre estas, contam-se o Guía de Pecadores, Memorial de la Vida Cristiana e Introducción al Símbolo de la Fe, publicadas entre 1556 e 1582. Cf. Bartolomé Bennassar;, Bernard Vicent. (2000). España. Los Siglos de Oro. Barcelona: Crítica, p.255.

${ }^{8}$ Cf, Pierre . Serquet (O.C.D).(1958). De La Vie Devote a La Vie Mystique, Paris: Desclée de Brouwer, pp. 40-73.

${ }^{9}$ Luis MuÑOz. Vida y Virtudes...., op.cit. [Prologo al Lector], s/p.

${ }^{10}$ Idem, ibidem.

${ }^{11}$ Cf. Santa Teresa. (1959). Epistolario. Madrid: La Editorial Catolica, BAC, 126-127. 
Carmelitas Descalços em Portugal, erigido na segunda década do século XVII ${ }^{12}$. No final de Quinhentos, é a própria Santa Teresa que registrava em Fundações [cap. 28, \& 41] que as monjas, «governavam-se pelos livros de Frei Luis de Granada e Frei Pedro de Alcântara» ${ }^{13}$. O carmelita descalço Frei Juan de Jesus Maria, Provincial da Ordem, subministrava orientações aos Mestres de Noviços para que adotassem, além dos livros de santos e doutores da Igreja, as obras de Frei Luis de Granada, mais as do Mestre Juan de Avila, do Doutror Diego Perez de Valdivia, do Padre Arias e as obras de Santa Teresa ${ }^{14}$.

Em outras casas religiosas também foi possível encontrar obras Luis de Granada. Na Chronica dos Carmelitas, Frei José Pereira de Santa Ana ${ }^{15}$ relata que o livro de Oração e Meditação foi lido por religiosos carmelitas da Ordem, entre os quais, designadamente, Frei Estevão da Purificação, tido por um dos mais assíduos leitores de Granada.

Chegoulha à mão no mesmo tempo o livro da Oração, e Meditação do Venerável Padre Fr. Luiz de Granada, um dos mais esclarecidos professores do sagrado Instituto Dominicano: e assim que o leo, reflectindo na pureza das suas sólidas doutrinas, logo o recebe por Mestre do seu espírito, usando daqueles santos exercícios pela sua mesma ordem, e confessava, que devia a sua felicidade, primeiro a Deos, que lha concedera, e depois àquele santo varão, que o instruira para a saber conservar ${ }^{16}$

Na Chronica dos Eremitas da Serra da Ossa, encontra-se citada a versão de Granada a respeito da obra de S. João Climaco, vertida do latim para o espanhol, «em benefício das almas mais dadas ao Senhor pelo caminho da contemplação e o ilustrou com as suas notas.» ${ }^{17}$. A tradução realizada também por Granada a partir

12 ANTT, mss n. 683, «Catálogo dos Livros que há no Convento de Carmelitas Descalços do Deserto de Santa Cruz do Bussaco». Do Frei Lui de Granada há dois exemplares do Compendio de Doutrina Crista, de 1559 e outra edição de 1622; o Guia de Pecadores, de 1572.

13 Teresa DE Jesus. (1995). Fundações. cap. 28, \& 41. In: Obras Completas. São Paulo: Ed. Loyola, p. 736.

${ }^{14}$ Fr. Juan JESUs MARIA. Instruccion que Dá ao Maestro de Novicios, tomo segundo [apud Luiz Muñoz, op.cit. pp. 207v. $\left.{ }^{\circ}-208\right]$.

${ }^{15}$ Frei José Pereira DE SANTA ANA. (1745-1751). Chronica dos Carmelitas da Antiga, e Regular Observancia Nestes Reinos de Portugal, 2 tomos, Lisboa, Herdeiros de António Pedroso Galrão, p. 16.

${ }^{16}$ Idem, p. 166.

${ }^{17}$ Frei Henrique SAnto AnTonio.(1745 - 1752). Chronica dos Eremitas da Serra de Ossa No Reyno de Portugal e dos que Florescerão em Mais Ermos da Christandade, tomo I, Lisboa: Francisco da Silva, p. 136. 
do livro Contemptus Mundi alcançou várias edições ${ }^{18}$. A versão espanhola, sob forma «romanceada», daria assim mais impulso à divulgação desta obra, mais conhecida como Imitação de Cristo, cuja autoria se atribui a Tomás de Kempis.

Os textos de Frei Luis de Granada tiveram um largo acolhimento entre os frades da Arrábida, em Portugal, ao ponto de, em diversas obras dos capuchos, se encontrarem referências aos textos do dominicano espanhol. Vê-se isto em vários livros contendo transcrições de inúmeras passagens dos seus escritos. É o próprio Frei Afonso de Medina ${ }^{19}$ que destaca na introdução ao seu Tratado a importância do Libro de la Oración y Meditación de frei Luis de Granada.

O que aqui disser será como um summario do muito que os outros dizem. Se alguem quiser ver isto mais copiosamente, quem se occupar na meditaçam ha o livro da Oraçam do Padre Fr. Luis de Granada, que a meu juizo ninguem te hoje escreveo melhor desta materia ${ }^{20}$.

Por outro lado, nas páginas do livro de Medina colhem-se não poucas afinidades com o texto de Granada. À semelhança deste último, Medina valorizava a oração mental sem, no entanto, condenar a vocal; o tema da meditação sobre a Paixão, a distribuição das vidas de meditação, exceto algumas variantes, são em quase tudo coincidentes nas duas obras ${ }^{21}$.

A fonte de inspiração proporcionada pela obra de Granada pode ser detectada em Motivos Spirituales, de Frei Rodrigo de Deus ${ }^{22}$. Maria Idalina Rodrigues apontou a linha de parentesco que existe entre o Jardim Espiritual, de Pedro de Santo Antônio ${ }^{23}$, e as obras de Granada, tais como o Compêndio de Doutrina

18 Nas palavras de Luiz MuÑoz foi o Padre Hiriberto Rousveydo da Companhia de Jesus, no segundo decênio do século dezessete, que atribuiu a autoria do livro ao flamengo Tomas de Kempis, canônico regular da Ordem de Santo Agostinho. A autoria já havia sido concedida a Juan Gerson. Na tradução de Granada aparece no título Recopilados de Diversos Autores, por el R. P.F. Luis de Granada de la Orden de S. Domingos (cf. MuÑOZ, op. cit., p. 187v. ${ }^{\circ}$ ).

${ }^{19}$ Frei Afonso MedinA. (1611). Hum Tratado que com Poucas, Breves e Claras Palavras Fala de Todos os Modos e Maneiras de Oração. Lisboa, Pedro Craesbeeck.

${ }^{20}$ Medina, Tratado..., op .cit., prólogo, (s/p).

${ }^{21}$ Ver a esse respeito a comparação realizada por Maria Idalina RODRIGUES em Frei Luis de Granada e a Literatura de Espiritualidade em Portugal, Tese de Doutorado em Filologia Romância. Universidade de Lisboa, 1976, pp. 1460-61.

${ }^{22}$ Frei Rodrigo DeUS. (1976). Motivos Spirituaes. Lisboa, Pedro Craesbeeck, 1611; ver também Maria Idalina Rodrigues. Frei Luis de Granada..., vol. II, p. 1450.

${ }^{23}$ Pedro de SAnto Antonio. (1632). Jardim Spiritual Tirado da Doctrina dos Sanctos, e Valoens Spirituaes. Lisboa, Matteus Pinheiro. 
Cristã, o Manual de Oraciones ou o Memorial de la Vida Cristiana ${ }^{24}$. Exactamente como em Granada, Rodrigo de Deus tece elogios à oração mental e reconhecia o valor da oração vocal, sobretudo para os principiantes. A mesma matriz discursiva de Frei Luis ordenava as meditações do capucho da Arrábida na perspectiva da via purgativa.

No decorrer de Seiscentos o nome de Granada continuou no apogeu, vários religiosos, famosos pela sua devoção no campo da alta espiritualidade, admiravamno e seguiam-no como seus discípulos, entre os quais o Padre Manuel Bernardes (1644-1710) e Frei António das Chagas (1631-1682).

No entanto, as obras de Granada iriam ser apropriadas não só no campo da literatura religiosa mas também no campo da produção iconográfica. Segundo Vitor Serrão, as tábuas com $A$ Virgem e o Menino e a Dolorosa, do pintor de Badajoz, Luís de Morales, conhecido como el Divino, do último quartel do século XVI, «são ecos formais das teses das postrimerías de Frei Luís de Granada, [..] eloquentes convites à oração nos oratórios domésticos na Península e em terras do Novo Mundo» ${ }^{25}$. Este artista que circulava pelas altas rodas intelectuais onde era forte a presença do pensamento granadino compreendeu o valor da imagem no processo oracional, daí que tenha investido na produção de tabuinhas. Ou seja, em retábulos devocionais para uso doméstico que obtiveram grande popularidade no final de Seiscentos e em todo o decorrer do século XVII na Península Ibérica. Os temas de sua preferência eram os da Paixão, pintados com notável realismo ${ }^{26}$. Eis, pois, como José Serrão descreve o artista:

Luís de Morales não foi só um pintor de clientelas provinciais, como se supunha,mas sobretudo um erudito artista, ligado aos meios espirituais renovadores da Igreja. [...] Peças como, por exemplo, o Cristo na coluna e São Pedro Arrependido, de Morales, existente na Catedral de Nuestra Señora de la Almudena, em Madrid, revelam esse complexo mundo espiritual da sua pintura, ligada à influência marcante que recebeu do pensamento renovador que o mundo dominicano, sobretudo com Frei Luís de Granada, lhe pudera transmitir. ${ }^{27}$ [grifo meu].

${ }^{24}$ Idem, p. 1461.

${ }^{25}$ Vitor SERRÃO. (2008). «O Pintor Régio Fernão Gomes, O Mosteiro da Anunciada e a Fundação da Irmandade de São Lucas, Corporação dos Pintores de Lisboa, em 1602» In: Ana Cristina GomeS, Jose Augusto Mourão, José Eduardo Franco, Vitor Serrão, (Coords.), Monjas Dominicanas. Presença, Arte e Patrimônio em Lisboa, Lisboa: Alétheia Editores, pp. 112 e 121.

${ }^{26}$ Idem, p. 121.

${ }^{27}$ Idem, p. 121. 
Frei Luís de Granada, segundo Victor Serrão, esteve ligado à seleção e definição da representação iconográfica da antiga igreja do Mosteiro de São Domingos, em Évora, hoje destruída ${ }^{28}$. O programa pictural com a Virgem e o Menino e São João Batista de grande plasticidade, é sem dúvida, como nenhum outro, um convite ao recolhimento e à oração.

Os livros de Frei Luís de Granada tiveram uma ampla aceitação por parte de muitos leigos, principalmente entre a aristocracia mais devota. $\mathrm{O}$ rei Felipe II tinha as obras do mestre granadino. Nos últimos tempos antes de sua morte, acamado, Felipe II contava em sua estante com cerca de quarenta livros espirituais, dentre os quais as obras de Frei Luís de Granada, de Teresa de Ávila e de Louis de Blois. Os livros de Luis de Granada estavam entre os preferidos de Felipe II, lidos comumente pela infanta Isabel ${ }^{29}$.

\section{A ESPIRITUALIDADE DE FREI LUÍS DE GRANADA}

Segundo Silva Dias, foi no colégio dominicano de S. Gregório de Valladolide, Espanha, que Frei Luís travou contato com as obras espirituais do norte da Itália ${ }^{30}$. Em Escalaceli, onde ingressou em 1534, nasceu a força do seu amadurecimento espiritual. A seguir, quando ia decorrido o ano de 1551, tomou o caminho de Portugal impelido pela atividade missionária e ali escreveu grande parte de sua obra. Nas palavras do seu biógrafo-mor, Álvaro Huerga, foi justamente em Escalaceli, que encontrou o seu método e descobriu o «mistério de Cristo» e a via interior e afectiva da oração e da prática cristã e onde, ademais, sofreu a grande influência do beato Juan de Ávila ${ }^{31}$. Este método, o da oração mental, tematizada n'O Libro de la Oración y Meditacion ${ }^{32}$, esteve sempre presente no cerne das suas preocupações. Ele afirmava que o homem mais facilmente eleva o seu coração a Deus se adotar a oração mental.

${ }^{28}$ Idem, p. 122.

${ }^{29}$ Henry KAmEn.(2003). Filipe da Espanha. Tradução de Vera Mello Joscelyne. Rio de Janeiro: Record, p. 449.

30 José Sebastião da Silva Dias. (1960). Correntes de Sentimento Religioso em Portugal, Coimbra, Editora da Universidade de Coimbra, p. 300

${ }^{31}$ Cf. Alvaro Huerga. ( 1988). Fray Luis de Granada. Una Vida al Servicio de la Iglesia, Madrid: La Editorial Catolica, Biblioteca de Autores Cristianos.

32 Frei Luís de Granada. (1562). Libro de la Oracion y Meditacion. En El Qual se Trata de la Consideracion de los Principales Mysterios de Nuestra Fé. Com Otros Três Breves Tratados de la Excelência de las Principales Obras Penitenciales que Son: Limosna, Ayuno y Oracion [...] En Lisboa: Por Antonio Aluarez. 
Vale dizer que a imaginação gozava de foros de primazia na condução da sua oração e por meio dela reafirmava o valor da meditação na paixão de Jesus, tal como Louis de Blois ${ }^{33}$ que insistia na necessidade de exercitar a memória na Humanidade de Cristo e de exercitar o seu sofrimento em cada momento do suplício da $\mathrm{Cruz}^{34}$. A meditação imaginativa ou imaginária difundida pela Vida Christi, e mais tarde retomada nos exercícios de Loyola, teve deste modo ampla aceitação no círculo de todos os que no século XVI se interessavam pelos exercícios de alta espiritualidade. Talvez por esta a razão o Libro de la Oración tenha alcançado tanto sucesso editorial e acabasse por ser arrolado no Índex inquisitorial. Resultado: ao assumir a defesa da via afectiva, Frei Luís abriu espaço, sem o querer, a um confronto com a posição intelectualista ${ }^{35}$.

Mas se Granada defendia a oração mental, de maneira nenhuma descartava a oração vocal, pois ele entendia que esta última era absolutamente necessária aos iniciantes da vida devota e aos incapazes no acesso às vias superiores da oração mental. É certo que ele condenava os excessos da oração vocal quando rezada de forma apressada e esvaziada de sentimento ${ }^{36}$. Logo, por tudo isto, Luís de Granada corporificou uma forte tendência que se fez sentir no seu tempo, ao mesmo tempo que atualizou uma tradição herdada dos místicos do Norte, como Henrique Hárfio e Tauler, que insistiam nas vantagens da oração mental sobre a vocal ${ }^{37}$. Contudo, se as afinidades entre os místicos de Estrasburgo e Colônia existiam realmente, nada autoriza a pensar que Granada os tenha lido em primeira mão, ainda que haja uma

33 «Regla de la Vida Espiritual: Como se Há de Fazer a Meditaction Cerca de la Passion de Christo, y que lo Avemos de Considerar, no Solo como Dios, Sino Tambiě como Hombre», cap. XXI, in Obras de Ludovico Blosio, Abad Liciense, Monge de la Orden de San Benito, traducidas de latin em romance por el Meaestro Fray Gregorio de Alfaro, Abad del Monasterio de Nuestra Señora del Buesso, Monge de la misma Orden, natural de Cordova. Dedicadas a la Serenissima Reyna del Cielo, Madre de Dios, e Señora Nuestra de Atocha, En Madrid: por Juan de la Cuesta, año 1619, pp. 21-22.

${ }^{34}$ Ver o Livro da Oração; Guia de Pecadores e Manual de Diversas Orações.

${ }^{35}$ Segundo Emílio Colunga, em quase todos os períodos da história ocorreram confrontos entre místicos e não místicos. Não obstante, os aspectos mais destacados que separam os dois lados oponentes são a valorização da oração mental, o entendimento da Graça divina na vida do homem, as discussões sobre a frequência do sacramento da eucaristia, a posição frente à expansão da alta espiritualidade, o critério na hierarquização das virtudes e a divulgação em romance dos livros devotos (Fr. Emílio Culunga. (1914). «Intelectualistas y Místicos en la Teologia Española del Siglo XVI», La Ciência Tomista, vol. IX, pp. 209 e ss).

${ }^{36}$ Frei Luís de GranADA. Memorial da La Vida Cristiana, p. 62.

${ }^{37} \mathrm{O}$ parentesco do pensamento granadino com os místicos do Norte é posto em evidência por Silva Dias. Veja-se da sua autoria Correntes de Sentimento Religioso em Portugal, op. cit., p. 311. Ver de Hárfio, Espelho da Perfeição; do Pseudo-Taulero, Exercícios; de Luis de Blois, Instituição Espiritual e Outros Opúsculos; de Dionísio Ryckel, Pérola Evangélica. 
grande proximidade entre a defesa em prol dos leigos feita pelo espanhol dominicano e a insistência de Tauler sobre o alcance da perfeição cristã aberta a todos, bem como a ênfase na defesa da oração mental ${ }^{38}$.

Segundo Silva Dias e Álvaro Huerga, não só os místicos do Norte contribuíram para a formação do pensamento granadino, mas também a escola italiana, em particular a de Savonarola e a de Batista de Crema, que influenciou o dominicano espanhol $^{39}$. Outros textos tiveram ascendência sobre Granada. Os de S. Boaventura, por exemplo. Outra influência que o marcou para toda a vida foi a do Beato Juan de Ávila por quem ele nutria a maior admiração ${ }^{40}$. Os exercícios de Inácio de Loyola também o inspiraram, e bastante ${ }^{41}$.

De empréstimos provenientes de distintas correntes espirituais e no confronto entre elas, Frei Luis de Granada produziu a sua obra. Integrado no campo maior do pietismo europeu, o dominicano granadino mergulhou nos livros do Antigo Testamento, bem como no Novo Testamento e nas Epístolas de São Paulo. Suas obras registram a sua vasta erudição onde busca referências desde pensadores da Antiguidade Clássica como Aristóteles ${ }^{42}$ até um amplo leque de autores da Igreja Católica, de Santo Agostinhoo ${ }^{43}$, S. Gregório ${ }^{44}$, S. Jerônimo ${ }^{45}$, Santo Ambrósio ${ }^{46}$, São Tomás de Aquino ${ }^{47}$, Santo Anselmo ${ }^{48}$, todos largamente citados em seus escritos.

\section{GRANADA E A ESPIRITUALIDADE DE SEU TEMPO}

A atração exercída pela espiritualidade mística nos séculos XVI e XVII, na Península Ibérica, explica em parte o interesse que os livros de Granada suscitaram.

${ }^{38}$ Maria Idalina RodriguES, Frei Luís DE GRANADA...op.cit., vol. II, p. 944.

39 Ver José Sebastião DA SILVA DIAS. Correntes de Sentimento... op.cit. pp. 304-305. Confira ainda de Marcel Bataillon.(1996). Erasmo y España. México. Fondo de Cultura Económica, pp. $595,596$.

${ }^{40}$ Ver a respeito o livro de HuERga, Fray Luis de Granada.., op.cit.

${ }^{41}$ José Sebastião DA Silva Dias. Correntes de Sentimento...op. cit., p. 305.

${ }^{42}$ Ver Guia Para Pecadores. (2008) A Riqueza da Virtude e o Caminho Para Alcançá-la, Rio de Janeiro: Thomas Nelson Brasil, pp. 21, 22, e 32. [edição mais recente publicada no Brasil].

${ }^{43}$ Idem, pp. 22, 25, 33, 41, 69 e 72.

${ }^{44}$ Idem, pp. 24, 125.

${ }^{45}$ Idem, pp. 24, 131.

${ }^{46}$ Idem, p. 58

${ }^{47}$ Idem, pp. 26 e 27.

${ }^{48}$ Idem, p. 56. 
Este é, sem dúvida, o período de grande difusão de obras de alta espiritualidade, motivo por que muitas obras de místicos da região Reno-Flamenga foram traduzidas do latim para o português ou para o espanhol, o mesmo acontecendo com obras provenientes de Itália ${ }^{49}$.

Se os livros do dominicano granadino chamaram a atenção do grande público, este fato, antes de mais nada, tem que ser visto à luz deste movimento. A título de exemplo, cite-se o Libro de la Oración y Meditación, editado em 1554, que continha modelos de oração mental e serviu de bússula nos caminhos da alta espiritualidade. Dele tiraram proveito os principantes e os iniciados ${ }^{50}$. A prática da oração mental, depois que foi sistematizada pela Devotio Moderna, tendeu a ser apropriada por leigos piedosos na Península Ibérica do século XVI. Divulgada por muitos escritores espirituais do século anterior, ela ganhou impulso nas mãos de religiosos como Juan de Ávila, por exemplo, de quem Frei Luis de Granada foi um herdeiro espiritual ${ }^{51}$. Todos eles, em suma, a seu modo, atualizaram a doutrina que os teólogos renano-flamengos no seu tempo faziam da oração mental enquanto prática capaz de conduzir o crente no caminho da revelação ${ }^{52}$.

Qualquer pessoa podia iniciar-se nos exercícios da vida contemplativa, ensinava Granada, e compartilhava uma idéia cara a outros espirituais da sua época, como D. Hilário Brandão (C.R.S.A), que defendia no seu livro Voz do Amado ser a «via unitiva» um caminho acessível a todos ${ }^{53}$. No início da década de setenta de Quinhentos, D. Gaspar de Leão, então a viver em Goa, advogava no seu Desengano de Perdidos que a teologia mística por ser superior à escolástica permitia ao leigo poder ascender às vias do amor unitivo ${ }^{54}$.

49 José Sebastião DA SiLva DiAS. (1960). Correntes do Sentimento Religioso em Portugal, 2 vols, Coimbra, Ed. da Universidade de Coimbra.

${ }^{50} \mathrm{O}$ Libro de la Oración y Meditación conheceu várias edições. Constam do acervo da Biblioteca Nacional de Lisboa as seguintes edições: Salamanca, 1567, 1570, 1572, 1573,1577, 1579; Gerona, 1558; Lisboa, 1592 e 1612; Barcelona, 1615. Na Biblioteca Geral da Universidade de Coimbra encontram-se as edições de Salamanca, 1573; Lisboa, 1592 e 1612. Na Biblioteca de Braga, a de Salamanca, 1573; Lisboa, 1592. Na Biblioteca de Évora, as de Salamanca, 1584 e 1586; Lisboa, 1592. E, finalmente, na Biblioteca de Leiria, a de Lisboa, 1612.

${ }^{51}$ Ver o livro de Alvaro HuERGA. (1988). Fray Luis de Granada ...., pp. 45-46.

52 Alain DE LIBERA. (1968). La Mystique Rhénane. D'Albert le Grand à Maitre Eckhart, Paris: Ed. du Seuil, 1994, pp. 41-46.; ver também Louis CogNET. Introduction aux Mystiques Rhéno Flamands, Paris: Desclée, p. 46.

${ }^{53}$ Maria de Lurdes Correia Fernandes. (1993). Introdução a Brandão, Hilário - Voz do Amado. Lisboa: Ed. Presença, pp. 10-28.

54 Cf., Maria DE Lourdes BelChIOR. (1994). «Gaspar de Leão», em Antologia de Espirituais Portugueses, Lisboa: Imprensa Nacional, Casa da Moeda, pp. 260-262 e 286-287. 
Frei Luís de Granada defendeu este mesmo princípio, se bem que isso the tivesse custado vários dissabores. Além de censurados, os seus livros foram colocados na lista do Índice de Valdés, de $1559^{55}$. O famoso teólogo Melchor Cano (O.P) via sombras de «alumbradismo» na literatura de alta espiritualidade produzida na época. A censura ao Catecismo $^{56}$ e a condenação do Arcebispo Carranza, são, entre inúmeros exemplos, os mais marcantes da repressão inquisitorial que se abateu contra todos os que se pronunciavam em favor desta prática oracional. Se a literatura ascético-mística ainda ofuscava os espíritos pela sua intensidade à época da ascensão de Felipe II ao trono, após a repressão levada a cabo pelos inquisidores ela não deixou, apesar de tudo, de se desenvolver em alguns meios religiosos. Foi o que se verificou no seio da reforma carmelitana após a exegese de Teresa de Jesus e de S. João da Cruz, não obstante as acusações e suspeitas de iluminismo ${ }^{57}$.

$\mathrm{O}$ interesse pela vida contemplativa iria continuar assim a seduzir muita gente em todo o século XVI, e também no século XVII. O mosteiro de Santa Cruz dos religiosos carmelitas descalços é, por si, uma referência simbólica da importância que a vida contemplativa e a oração mental tiveram naquele tempo ${ }^{58}$.

Depois da censura aos seus livros, Frei Luís de Granada jamais deixou de escrever. É assim que em 1561 editou um pequeno volume com três opusculos dedicado à infanta D. Maria, sob o título Memorial de lo que Debe Hacer el Cristiano, Tratado de Algunas Muy Devotas Oraciones, Vita Christi, cujo êxito de vendas foi imediato ${ }^{59}$. Os livros desde logo encantaram, porque ofereciam ao leitor lições espirituais, de fácil entendimento. O terceiro opúsculo oferecia uma série de meditações sobre a vida de Cristo. Malgrado a censura, nunca, em momento algum, Granada desistiu de defender o primado da oração mental por parte dos leigos. $\mathrm{Na}$ apresentação do Vita Christi ele ministra ao leitor cristão as seguintes instruções:

55 Cathalogus Librorum Qui Prohibentur Mandato Ill. Et Rev. D. Ferdinandi de Valdés... (Valladolid, 1559), p. 41, apud A. HuERGA. Fray Luis de Granada. op.cit., p. 153. De Frei Luís DE GranADA constam: De la oración y Meditación, Guia de Pecadores, Manual de Diversas Oraciones, Espirituales Exercicios.

56 Bartolomé CARRAnZa. (1558). Comentarios Sobre el Catechismo Christiano. Anvers, Martín Nicio.

${ }^{57}$ Marcel Bataillon. (1979). Erasmo y España, Madrid, F.U.E, pp. 699-737.

${ }^{58}$ Pinharanda Gomes. (1983). Caminhos Portugueses de Teresa de Ávila. Braga: Pax.

${ }^{59}$ Foi editado em Lisboa, por Blavio, em 1561 (cf. HuERGA, Fray Luis de Granada, op.cit, p. 161). 
El tratado precedente, cristiano lector, sirve para el uso de la oración vocal, la cual con palavras humildes y devotas habla y negocia con Dios [...]. Más el tratado presente servirá al uso de la oración mental, que se hace en lo intimo del corazón, en la cual entreviene la consideración de las cosas celestiales [...]. Y entre otras muchas cosas que hay que considerar, una de las más principales es la vida y la pasión de Cristo $[\ldots]^{60}$.

Finalmente o Concilio de Trento acabou por retirar os seus livros do Índice dos Livros Proibidos, medida que naturalmente o alivou das pressões inquisitoriais e lhe permitiu continuar a produzir e a divulgar as suas obras. Contudo, dali para a frente Granada optou por não mais afrontar os princípios doutrinais defendidos pelos censores.

Se o tema de maior ênfase nos seus escritos é a alta espiritualidade, a verdade é que Granada não descuidou o que se poderá chamar a formação do bom cristão e a qualidade da vida religiosa. Para tanto preocupou-se em orientar os fiéis na prática da virtude e na arte de vencer os vícios com o seu Guia Para Pecadores, bem como alcançar o caminho da perfeição e do bem viver, tema, de resto, recorrente no seu Memorial de La Vida Cristiana ${ }^{61}$. Uma das suas preocupações que mais instigantes, foi escrever não só para religiosos, mas também para os recéminiciados nos assuntos de fé.

Ele prestou igualmente um grande cuidado à qualidade dos sermões e à prática religiosa. Os treze sermões que acompanham o volume editado em 1559, do Compêndio de Doutrina Cristã ${ }^{62}$, constituem um perfeito instrumento de pregação cristã destinado a ser lido nas igrejas quando os sacerdotes habilitados se mostrassem inábeis para elaborar os seus próprios sermões ${ }^{63}$. A esta escala, os seus escritos refletiam o pensamento dominante na Igreja Católica, após sobretudo o Concílio de Trento, cujo propósito era melhorar a qualidade do ensino religioso ${ }^{64}$.

${ }^{60}$ Obras de Fray Luis de Granada, vol. XI, edición de J. Cuervo, Madrid, Fuentenebro, 1906-08; pp. 353-354. [citado por Huerga, op. cit, pp. 161-162].

${ }^{61}$ Consultamos a edição de 1593, editada em Barcelona por Jayme Cendrat.

62 Compendio de Doctrina Christãa Recopilado de Diversos Autores que Desta Matéria Escreverão, pelo R.P.F. Luys de Granada. Provincial da ordem de S. Domingos. Acrescentarão se o Cabo Treze Sermões das Principaes Festas do Anno: pelo mesmo Autor.., (1559). Lisboa. Ioannes Blauio de Agripina Colonia, Impressor del Rey nosso Senhor.

${ }^{63}$ Ver também sobre o assunto, Maria Idalina RoDRIGUES. Frei Luís de Granada..., 1976, vol. 1, p. 61; ver da mesma autora, «Frei Luís de Granada. Sermões para o Povo Português», Via Spiritus, 11 (2004), pp. 27-44.

${ }^{64}$ N. DAvidson. (1991). A Contra-Reforma. São Paulo, Martins Fontes. 
Qualquer que seja o ângulo por se se estude a figura de Frei Luís de Granada, há um ponto que nos parece consensual: acima de tudo ele foi um espelho dos anseios de uma parte da sociedade católica do seu tempo. Se por um lado a sua escrita penetrou fundo na alma de uma significativa parcela da sociedade ibérica porque foi de encontro às ansiedades espirituais dos seus contemporâneos, por outro o estilo com que transmitiu as suas idéias funcionou como uma mola propulsora na divulgação da sua palavra. Com as suas prédicas, seduziu muitos leitores no caminho da alta espiritualidade.

\section{BIBLIOGRAFIA}

\section{Fontes Primárias}

AN/TT. (Arquivo Nacional da Torre do Tombo (Lisboa). «Catálogo dos Livros que há no Convento de Carmelitas Descalços do Deserto de Santa Cruz do Bussaco». mss n. ${ }^{\circ} 683$.

\section{Impressas}

Carranza, Bartolomé. (1558). Comentarios Sobre el Catechismo Christiano. Anvers, Martín Nicio.

López, J. (1615). Quarta Parte de la historia General de Santo Domingo y de su Orden de Predicadores. Valladolid: Fernández de Córdoba.

MedinA, Frei Afonso. (1611). Hum Tratado que com Poucas, Breves e Claras Palavras Fala de Todos os Modos e Maneiras de Oração. Lisboa, Pedro Craesbeeck.

MONFORTE, Frey Manoel. (1696). Chronica da provincia da Piedade. Primeira capucha de toda ordem... de nosso Seraphico S. Francisco. Lisboa. Na Officina de Miguel Deslandes.

Muñoz, Luis. (1639). Vida y Virtudes Del Venerable Varon El P.M. Fray Luis de Granada, de la Orden de Santo Domingo. En Madrid. Por Maria de Quiñones.

SANTA ANA, Frei José Pereira de. (1745-1751). Chronica dos Carmelitas da Antiga, e Regular Observancia Nestes Reinos de Portugal, 2 tomos, Lisboa, Na Officina dos Herdeiros de António Pedroso Galrão.

Santo Antonio, Frei Henrique. (1745 - 1752). Chronica dos Eremitas da Serra de Ossa No Reyno de Portugal e dos que Florescerão em Mais Ermos da Christandade. 2 tomos. Lisboa: na Officina de Francisco da Sylva.

SAnto Antonio, Pedro de. (1632). Jardim Spiritual Tirado da Doctrina dos Sanctos, e Valoens Spirituaes. Lisboa, Matteus Pinheiro.

JESUs, Teresa de. (1995). Obras Completas. São Paulo: Ed. Loyola

\section{Obras de Frei Luís de Granada consultadas:}

GRANADA, Fray Luis (1562). Libro de la Oracion y Meditacion. En El Qual se Trata de la Consideracion de los Principales Mysterios de Nuestra Fé. Com Otros Três Breves Tratados de la Excelência de las Principales Obras Penitenciales que Son: Limosna, Ayuno y Oracion [...] En Lisboa: Por Antonio Aluarez.. 
GRANADA, Fray Luis (1555). Breve tratado de tres principales exercícios. Évora: Andrés de Burgos.

GRANADA, Fray Luis (1557). Manual de diversas oraciones y exercicios espiritules. Lisboa, Juan Blavio de Colonia.

GranadA, Fray Luis (1593). Memorial de La Vida Cristiana. Barcelona: Por Jayme Cendrat.

GRANADA, Fray Luis (1563) Tratado de algunas muy devotas oraciones para provocar al amor de Dios. Lisboa Ioannes Blavio.

GRANADA, Fray Luis (1559) Compendio de doctrina christiãa. Lisboa: Ioannes Blavio.

GRANADA, Fray Luis ( 1561) Memorial de lo que debe hacer el Cristiano. Lisboa: Ioannes Blavio.

GranadA, Fray Luis (2008). Guia de Pecadores. A Riqueza das Virtude e o Caminho Para Alcançá-la. Rio de Janeiro: Thomas Nelson Brasil.

GRANADA, Fray Luis (1583). Introducción del simbolo de la fe. 4 tomos. Salamanca: Herederos de M. Gast.

GRANADA, Fray Luis (1989). Introducción del Símbolo de la Fe. Madrid: Cátedra.

\section{Livros e artigos}

ANDRÉS, Melquíades. (1976). La Teologia Española en el Siglo XVI. Madrid: Editorial Católica.

ANSELMO, Antonio Joaquim. (1926). Bibliografia das Obras Impressas em Portugal no Século XVI. Lisboa: Oficinas Gráficas da Biblioteca Nacional.

AROUCA, João Frederico de Gusmão. (2003). Bibliografia das Obras Impressas em Portugal no Séc. XVII. Lisboa: Biblioteca Nacional.

Bataillon, Marcel. (1979). Erasmo Y España, Madrid: F.U.E.

BAtAillon, Marcel. (1996). Erasmo Y España, México: Fondo de Cultura Económica.

BELCHIOR, Maria de Lourdes. (1994). «Gaspar de Leão» in: Antologia de Espirituais Portugueses. Lisboa: Imprensa Nacional - Casa da Moeda.

Bennassar, Bartolomé; Vicent, Bernard. España. (2000)..Los Siglos de Oro. Barcelona: Crítica.

Cognet, Louis. (1968). Introduction aux Mystiques Rhéno Flamands, Paris: Desclée.

Dias, José Sebastião da Silva. (1960). Correntes de Sentimento Religioso em Portugal. Coimbra: Editora Da Universidade de Coimbra.

FERNANDES, Maria de Lurdes Correia. (1993). Introdução a Brandão, Hilário - Voz do Amado. Lisboa: Ed. Presença.

Gomes, Pinharanda. (1983). Caminhos Portugueses de Teresa de Ávila. Braga: Pax.

Huerga, Álvaro. (1988). Fray Luis de Granada. Una Vida al Servicio de la Iglesia, Madrid: La Editorial Catolica. Biblioteca de Autores Cristianos.

LiBerA, Alain de. (1994). La Mystique Rhénane. D'Albert le Grand à Maitre Eckhart, Paris: Ed. du Seuil,

RODRIGUES, Maria Idalina. (1976). Frei Luís de Granada e a Literatura de Espiritualidade em Portugal. Tese de Doutorado em Filologia Romância. Universidade de Lisboa, 2 v. 
LIBERA, Alain de. (2004). «Frei Luís de Granada. Sermões para o Povo Português», Via Spiritus, 11, pp. 27-44.

SERrão, Vitor. (2008). «O Pintor Régio Fernão Gomes, O Mosteiro da Anunciada e a Fundação da Irmandade de São Lucas, Corporação dos Pintores de Lisboa, em 1602» In: Gomes, Ana Cristina, Mourão, Jose Augusto, Franco, José Eduardo, SERrão, Vitor (Coords.), Monjas Dominicanas. Presença, Arte e Patrimônio em Lisboa, Lisboa: Alétheia Editores.

SERQUeT, Pierre (O.C.D). (1958).De La Vie Devote a La Vie Mystique, Paris: Desclée de Brouwer, 
